\title{
MARCADORES CONVERSACIONAIS E DIALETOLOGIA: UM ESTUDO \\ COMPARATIVO ENTRE OS GÊNEROS
}

\section{CONVERSATIONAL BOOKMARKS AND DIALECTOLOGY: A COMPARATIVE STUDY AMONG GENDERS}

Marcia Zamariano

\author{
Doutora em Estudos da Linguagem pela Universidade Estadual de Londrina \\ E-mail: m_zamariano@hotmail.com
}

\author{
Anna Carolina Chierotti dos Santos Ananias \\ Doutoranda pela Universidade Estadual de Londrina \\ E-mail: annachierotti@yahoo.com.br
}

\section{RESUMO}

Os Marcadores Conversacionais (MCs), característicos à Língua Falada (LF), possuem fundamental importância no que se refere à conversação, pois são também responsáveis pela interação e compreensão por parte dos interlocutores. Este trabalho tem como objetivo principal analisar e comparar as divergências na utilização dos MCs entre um indivíduo do sexo masculino e outro do sexo feminino, em duas entrevistas realizadas pelo projeto Atlas Linguístico do Brasil (AliB). A análise comparativa aponta considerável diferença na quantidade e nos tipos de MCs utilizados pelos informantes.

Palavras-chave: Língua Falada. Marcadores conversacionais. Dialetologia.

\begin{abstract}
The Conversational Bookmarks (CBs), characteristic of Spoken Language (SL), have fundamental importance with regard to the conversation; they are also responsible for interaction and understanding by the interlocutors. This study aimed to analyze and compare the differences in the use of CBs between a male subject and another female, in two interviews for the project Linguistic Atlas of Brazil (AliB). The comparative analysis shows considerable difference in the amount and types of CBs used by informants.
\end{abstract}

Keywords: Spoken Language. Conversational Bookmarks. Dialectology. 


\section{INTRODUÇÃO}

O fator mais relevante que diferencia o ser humano de outros seres é a capacidade de comunicar e expressar seus pensamentos. Não há dúvidas de que outros seres e/ou animais possuem sua forma de comunicação. Esta, contudo, encontra-se em um nível básico cuja função pode ser principalmente, entre outras inúmeras ferramentas, a de emitir sinais de perigo ao grupo, a de marcar seu domínio sobre determinada área territorial e de viabilizar o reconhecimento, pelos pares da espécie, da época ideal ao acasalamento. O homem, todavia, diante de suas necessidades comunicativas, criou um sistema mais complexo para interagir com os demais membros de seu grupo e desenvolveu como base um código de fonemas (sons).

Entre os inúmeros meios de comunicação humana, a fala é considerada uma das que possui maior relevância. Por meio desta um indivíduo pode interagir com outros face a face e compartilhar o que sente através do que fala, dos seus gestos, olhares e de todas as características peculiares a essa manifestação humana.

Configura-se, assim, a importância de trabalhos voltados para a abordagem da linguagem oral. Nessa linha de raciocínio, este trabalho propõe-se, após fazer uma breve apresentação da importância da oralidade entre os seres humanos, a expor, sob outra perspectiva, o que vários estudos já comprovaram: que os seres humanos apresentam em sua fala repetições, frases truncadas, pausas, hesitações, elipses e elementos paralinguísticos, mesmo que estas pessoas sejam consideradas cultas. As constatações dessas afirmações estão comprovadas pelo projeto NURC/SP, pois seu corpus é constituído por subsídios recolhidos de informantes com formação universitária.

Partindo do conhecimento da existência e comprovação destas marcas na oralidade, objetiva-se comparar marcadores conversacionais empregados por informantes de gênero masculino e feminino de uma mesma região e que possuem características parecidas. As narrativas utilizadas neste trabalho, da questão referente aos temas para discursos semidirigidos, na qual o informante verbaliza um relato pessoal, foram retiradas do banco de dados do projeto Atlas Linguístico do Brasil (ALiB).

A opção por esta questão - relato pessoal - concentrou-se basicamente na condição de que o informante ${ }^{1}$ entrevistado se sente mais desinibido e, normalmente, esquece o fato de que está relatando para uma gravação de estudo, e, muitas vezes se emociona ao relembrar um momento marcante de sua vida. Assim, a partir de uma entrevista de cunho dialetológico, que possui um procedimento metodológico para coletar dados de fala de informantes em situações comunicativas naturais e espontâneas, serão analisados os marcadores conversacionais. Desta forma, busca-se uma pequena comparação de aspectos da fala entre um homem e uma mulher, pertencentes a uma mesma região e de idades aproximadas. 


\section{FUNDAMENTAÇÃO TEÓRICA}

A Linguística é a ciência que tem como objeto de estudo os fenômenos linguísticos, ocupando-se da descrição das línguas naturais, ou seja, a linguagem articulada. A língua é considerada uma atividade mental e um código utilizado pelo homem para expressar seus sentimentos, vontades e pensamentos; também é por meio dela que os falantes atuam e interagem em grupos sociais.

Segundo Borba (1972, p.37), a língua é uma parte ou uma manifestação da linguagem e possui função social. Esse ponto de vista recupera a posição do precursor da Linguística Moderna, Ferdinand de Saussure, que define a língua como social e a fala como individual. A primeira como algo adquirido e convencional; por meio dela o indivíduo é compreendido e se faz compreender, e também por ela que se exprimem as ideias; define-se pelo seu caráter abstrato sendo um produto da cultura. Já a segunda é o meio utilizado pelo homem para exprimir seus pensamentos, emoções; a fala é a língua em ação, portanto, a realização concreta da língua (SAUSSURE, 1972, p. 21-22).

Câmara Jr. (1981, p. 11) pondera que, por meio da linguagem, o ser humano é capaz de organizar o pensamento. Quando, por exemplo, uma criança adquire a capacidade de usar a língua dos adultos, consequentemente, desenvolve um potencial maior de raciocínio. $\mathrm{O}$ autor compreende que, entre as inúmeras funções da linguagem, há duas que se destacam: (a) possibilitar o pensamento em seu sentido lato; (b) permitir a comunicação ampla do pensamento assim elaborado. Para tanto, existem dois tipos de exposição linguística: a oral e a escrita.

A língua escrita e a língua falada possuem características diferentes como, por exemplo, a grande quantidade de construções sintáticas na escrita, o que não ocorre com tanta frequência na fala. Esse entendimento, de que os dois tipos de expressão são diferentes, não é suficiente para caracterizar dois sistemas linguísticos. Marcuschi (2001, p.16) explica que, atualmente, predomina a posição de que essas são, "atividades interativas e complementares no contexto das práticas sociais e culturais".

A seguir será apresentado um quadro no qual Koch (1992, p.68) apresenta algumas das diferenças mais perceptíveis entre a escrita e a oralidade:

\section{Quadro 1: Diferenças ente escrita e oralidade}

\begin{tabular}{|l|l|}
\hline \multicolumn{1}{|c|}{ FALA } & \multicolumn{1}{|c|}{ ESCRITA } \\
\hline Não planejada & Planejada \\
\hline Incompleta & Não fragmentada \\
\hline Pouco elaborada & Completa \\
\hline Predominância de frases curtas, simples ou coordenadas & Elaborada \\
\hline Pouco uso de passivas & $\begin{array}{l}\text { Predominância de frases completas, com } \\
\text { subordinação abundante. Emprego frequente }\end{array}$ \\
\hline
\end{tabular}

Fonte: Kloch (1192) 
Alguns estudiosos que defendem a preponderância da oralidade sobre a escrita, como Ong (1998, p.15), justificam que, por mais ricas que sejam todas as formas de expressão, a oralidade prevalece, o que pode ser percebido ao observar que das cerca de três mil línguas atualmente faladas, aproximadamente 78 tem literatura, e, centenas não possuem escrita. Dessa forma, a escrita nunca pode prescindir da expressão oral, pois esta pode existir sem a escrita, mas a escrita não existe sem a oralidade.

Reyzábal (1999, p. 25) também defende a primazia da oralidade e afirma que se deve partir da base da língua, que é oral. Portanto, é necessário que se desenvolva cada vez mais o interesse pela língua que o indivíduo possui na comunicação quotidiana, inclusive com suas imperfeições e inexatidões.

Porém, não se pode rejeitar a escrita, como já pensava Saussure, o qual apresentava a importância do discurso oral e considerava a escrita como complemento da oralidade e não como transformadora da verbalização. Marcuschi (2001, p.17) ainda considera que quando a escrita se fixa em uma sociedade, ela pode se impor de tal forma que seu valor social se torna superior à oralidade. $\mathrm{O}$ que se depreende diante das duas modalidades citadas, é que ambas possuem sua importância na sociedade que as utilizam.

\section{A ANÁLISE DA CONVERSAÇÃO}

Como o foco deste artigo é trabalhar a língua na oralidade a partir do estudo da interação verbal e não verbal em situações cotidianas dos seres humanos, descrevendo a forma de interação da sociedade entre si, de maneira formal e informal e na construção das identidades das pessoas, optou-se pelos princípios da Análise da Conversação (AC).

A AC tem suas origens nas décadas de 60 e 70, quando se preocupava essencialmente com a estrutura das conversações (MARCUSCHI, 2006, p.6). Os primeiros trabalhos da Análise da Conversação tiveram como bases a Etnometodologia e a Antropologia e Sociologia cognitivas, e objetivavam a descoberta do exame do comportamento diário de base de toda interação social. Conforme novas pesquisas foram se desenvolvendo, surgiu uma linha mais linguística de AC e, dessa forma, a intenção visa correlacionar fenômenos linguísticos e necessidades da interação.

Marcuschi (2006, p.15) explica que o objeto da AC são os processos conversacionais, focados na prática do dia-a-dia do ser humano. Para o autor, a conversação seria "uma interação verbal centrada, que se desenvolve durante o tempo em que dois ou mais interlocutoress voltam sua atenção visual e cognitiva para uma tarefa comum". Por conta disso, foca-se nas conversações ditas naturais e em elementos não apenas verbais, mas entonacionais, paralinguísticos e contextuais. 
Andrade (1998, p.142) se refere à unidade discursiva como enunciados conversacionais, os quais podem refletir a experiência do falante a respeito do que seja um bloco textual. Essa unidade apresenta uma regularidade bastante grande, transmite porções informacionais, preservando a propriedade de coerência temática de uma unidade maior: o texto. Rosa (1992 p. 16) afirma que a interação face a face do dia-a-dia apresenta alguns traços convencionalizados, refletidos em determinadas palavras ou expressões linguísticas. Estudos recentes utilizam o termo marcador para se referirem à ocorrência dessas expressões. Esses marcadores conversacionais, normalmente, delimitam a unidade discursiva e são conceituados diferentemente pelos pesquisadores da área. Neste trabalho, toma-se por base o conceito de dois estudiosos, os quais levam em consideração o seu funcionamento em língua portuguesa:

os recursos verbais que operam como marcadores formam uma classe de palavras ou expressões altamente estereotipadas, de grande ocorrência e recorrência. Não contribuem propriamente com informações novas para o desenvolvimento do tópico, mas situam-no no contexto geral, particular ou pessoal da conversação. Alguns não são sequer lexicalizados, tais como "mm", “ahã", "ué” e muitos outros. (MARCUSCHI, 1986, p. 62).

Castilho (1989, p. 273- 274 apud Galembeck $\left(2001^{2}\right)$ admite:

que todos os marcadores conversacionais (por ele denominados marcadores discursivos) exercem, genericamente, uma função textual, à medida que organizam e estruturam o texto. Essa função geral, porém, desdobra-se nas duas funções particulares indicadas a seguir: a função interpessoal e a ideacional. Essa duplicidade de funções faz com que existam dois tipos de marcadores: os interacionais (ou interpessoais) e os ideacionais (ou coesivos).

Os marcadores podem se manifestar das seguintes formas: os linguísticos - incluindo os prosódicos (pausas, alongamentos) e os verbais (lexicalizados e não lexicalizados) -, e, além destes dois, os não linguísticos: gestos, olhares, risos, entre outros. Em relação à posição no turno, Marcuschi (2006, p. 68) classifica os marcadores conforme apresentado nos quadros 2 e 3.

Quadro 2: Sinais do Falante

\begin{tabular}{|c|c|c|c|}
\hline $\begin{array}{l}\text { Pré-posicionado - no } \\
\text { início do turno }\end{array}$ & $\begin{array}{c}\text { Pré-posicionado - no início } \\
\text { de uma unidade } \\
\text { comunicativa }\end{array}$ & $\begin{array}{l}\text { Pós-posicionado - no } \\
\text { início do turno }\end{array}$ & $\begin{array}{l}\text { Pós-posicionado - no } \\
\text { início de uma unidade } \\
\text { comunicativa }\end{array}$ \\
\hline "olha" & "então" & "né" & “né" \\
\hline "veja" & “aí" & "certo?" & "não sabe?" \\
\hline "bom" & "daí" & "viu?" & "certo?" \\
\hline "mas eu" & "mas" & "entendeu?" & “entende?" \\
\hline "eu acho" & "assim" & "e então" & "de acordo?" \\
\hline "não não" & "por exemplo" & “é ou não é?" & "ta?" \\
\hline "certo, mas" & "agora veja" & "é isso aí" & "não é?" \\
\hline Etc. & Etc. & Etc. & Etc. \\
\hline
\end{tabular}

Fonte: Marcuschi (2006, p. 68) 


\section{Quadro 3: Sinais do Ouvinte}

\begin{tabular}{|c|c|c|}
\hline Convergentes & Indagativos & Divergentes \\
\hline "sim" & "será?" & "duvido" \\
\hline "claro" & "não diga?" & "discordo" \\
\hline "ahã" & "mesmo?" & "essa não" \\
\hline "pois não" & "é?" & "nunca" disso" \\
\hline "claro, claro" & "ué" & "calma" \\
\hline "isso" & "como?" & Etc. \\
\hline "ah sim" & "como assim?" & Etc. \\
\hline
\end{tabular}

Fonte: Marcuschi (2006, p. 68)

Podem ser entendidos da seguinte forma: os iniciais caracterizam o início ou a tomada de turno; os mediais são responsáveis pelo desenvolvimento do turno e os finais assinalam a passagem implícita ou explícita do turno.

Marcuschi $(1987)^{3}$, também divide os marcadores conversacionais em:

a) marcador simples - uma só palavra;

b) marcador composto - apresenta um caráter sintagmático;

c) marcador oracional - corresponde a pequenas orações que se apresentam nos diversos tempos e formas verbais;

d) marcador prosódico - associa-se a algum marcador verbal, mas realiza-se por meio de recursos prosódicos.

Os marcadores são, portanto, elementos que auxiliam no desenvolvimento interacional da atividade discursiva. A seguir, contextualiza-se o projeto $A L i B$, de onde foram retirados os dados analisados.

\section{PROJETO DO ATLAS LINGUÍSTICO DO BRASIL (ALIB)}

Segundo o Comitê Nacional do Projeto $A L i B$ (1999), é preciso ter uma visão da multidimensionalidade da língua no país, não apenas para efeito de precisar e demarcar espaços geolinguísticos, mas para que se possa também contribuir, de forma direta, para um melhor equacionamento entre a realidade de cada área e o ensino de língua materna que nela se processa.

Com este pensamento, reuniu-se uma equipe de pesquisadores que buscava "não só verificar as diferenças léxico-semânticas entre o português brasileiro e as diferenças regionais, mas também a investigação dos aspectos fonético-fonológicos, morfossintáticos e prosódicos na tentativa de delimitar os contornos, ainda que tênues, da língua portuguesa nas diferentes áreas do Brasil” (ALTINO, 2007, p. 65). 
Esse projeto de âmbito nacional tem como objetivos, conforme consta do Projeto elaborado pelo Comitê Nacional, descrever a realidade linguística estabelecendo isoglossas para que, a partir de um banco de dados que ofereça materiais em maior volume para o estudo da língua, pesquisadores dos diversos níveis dos cursos de Letras - Graduação, Pós-graduação e docentes possam analisar os dados coletados, contribuindo para o entendimento da língua portuguesa no Brasil como instrumento de comunicação diversificada. Ao final, espera oferecer subsídios para o ensino/aprendizagem da língua materna, muitas vezes, concebida como um sistema hermético que não admite variações e que dita regras rígidas a serem seguidas sem nenhum questionamento. A execução do ALiB, segundo o Comitê Nacional, divide-se em quatro etapas distintas, descritas nos tópicos a seguir.

A primeira etapa refere-se à concepção e à definição da metodologia - a preparação e implantação do projeto, a definição dos princípios metodológicos adotados para essa empresa, além do estabelecimento de critérios metodológicos para a pesquisa de campo. São eles:

Definição da rede de pontos: constituída por 250 localidades distribuídas por todo o território nacional, levando-se em consideração a extensão de cada região, os aspectos demográficos, culturais, históricos e a natureza do processo de povoamento da área. Foram, ainda, consideradas questões referentes aos limites internos e internacionais, e, analisados os pontos sugeridos por Nascentes, os quais, quando reconhecida à pertinência, foram mantidos (COMITÊ NACIONAL DO PROJETO ALiB, 2001, p. $8)$.

Definição do perfil e número de informantes: a amostra representativa dos falantes a serem entrevistados em cada localidade constante da rede de pontos ficou assim definida como segue:

- Nas capitais: oito informantes divididos entre ambos os sexos; distribuídos em duas faixas etárias - 18 a 30 anos e 50 a 65 anos - com escolaridade fundamental para quatro, dos oito informantes; e superior para outros quatro informantes entrevistados.

- No interior: quatro informantes divididos entre ambos os sexos, também nas duas faixas etárias citadas, com escolaridade fundamental.

- Para o perfil do informante permanece a condição de ser natural da localidade, ter profissão definida e estar inserido no contexto social local. Buscam-se informantes que tenham viajado pouco e cujos pais e cônjuge (quando for o caso) sejam preferencialmente nascidos na localidade. 
Elaboração do instrumento de coleta de dados: uma atenção especial recaiu sobre o instrumento de coleta de dados. Os pesquisadores do projeto elaboraram questionários que pudessem refletir os objetivos delineados, indicando com clareza as noções cujas denominações se pretende extrair dos informantes, os traços fonéticos e os tipos de frases recorrentes em cada região estudada. Dos encontros promovidos pelo Comitê Nacional, surgiram contribuições para o aperfeiçoamento dos questionários utilizados no trabalho de campo que está sendo realizado pela equipe de inquiridores do $A L i B$ por meio dos três instrumentos de coleta de dados: o questionário fonético-fonológico (QFF), composto de 159 questões; o questionário semântico-lexical (QLS) com 202 questões e o questionário morfossintático (QMS) que conta com 49 perguntas. Suas duas versões preliminares (publicadas em $1998 \mathrm{e}$ 2000) foram testadas em diversos inquéritos experimentais e analisadas nos encontros nacionais, chegando à versão definitiva publicada em 2001.

A segunda etapa é composta de trabalho de campo. Estabeleceu-se a prioridade da coleta dos dados nas capitais brasileiras ${ }^{4}$, seguida da coleta de dados nas demais localidades. As transcrições, fonética e grafemática dos dados, fazem parte das tarefas estabelecidas nesta fase do projeto. Para a realização das transcrições, definida nos princípios metodológicos, exigiu-se uma preparação cuidadosa da equipe de transcritores, precedida de ampla discussão e de exercícios de transcrições experimentais para que fossem estabelecidos os critérios a serem seguidos por todos os envolvidos nessa fase.

Para a terceira etapa do projeto, estão estabelecidas as metas de término das transcrições iniciadas na fase anterior e a continuação da análise dos dados. Segue-se a essa, a quarta etapa em que serão feitas a editoração e a publicação dos materiais.

Como anteriormente mencionado, este trabalho possui como objetivo geral levantar e descrever, sob outra perspectiva, os marcadores conversacionais presentes na fala de um informante homem e de uma informante mulher, com características semelhantes, a fim de fazer comparações e levantar uma hipótese para futuros trabalhos: "Há uma preponderância maior em algum dos gêneros? Ou seja, a fala do gênero masculino e a do gênero feminino se diferenciam na utilização dos marcadores conversacionais?".

Trabalhos realizados através dos dados do projeto NURC/SP já puderam comprovar que mesmo na fala uma de uma pessoa culta haverá repetições, frases truncadas, pausas, hesitações, elipses e elementos paralinguísticos. Portanto, os seres humanos utilizam de fato essas marcas linguísticas, mas há uma diferença entre o homem e a mulher? Deve-se levar em consideração que os dois informantes selecionados vivem em Curitiba, capital do Estado do Paraná; pertencem à 
segunda faixa etária, 50 a 65 anos; possuem ensino fundamental, são naturais da localidade, tem profissão definida e estão inseridos no contexto social local, características que os diferencia dos informantes do projeto NURC/SP. E ainda, busca-se informantes que tenham viajado pouco e cujos pais e cônjuge (quando for o caso) sejam preferencialmente nascidos na localidade.

\section{METODOLOGIA E ANÁLISE DOS DADOS}

A questão selecionada se refere a 001 do tópico "Temas para Discursos Semidirigidos", na qual se pede ao informante para relatar algum fato marcante em sua vida. Como já afirmado anteriormente, neste momento, o informante normalmente esquece do aparelho ligado para a gravação e assim, possivelmente, demonstra sua verdadeira fala do dia-dia.

A metodologia utilizada para este trabalho, em síntese, obedece às seguintes etapas: (1) levantamento da fundamentação teórica para embasamento do trabalho; (2) delimitação do corpus (pela extensão deste trabalho optou-se por analisar apenas duas entrevistas do $A L i B$ referentes à cidade de Curitiba-PR (um informante masculino e um feminino); (3) análise qualitativa dos dados, com auxílio dos modelos de classificação de Marcuschi (2006) e Chagas ${ }^{5}$ (2007); (4) considerações obtidas ao final do trabalho.

As entrevistas aparecem com as abreviações INQ para inquiridor e INF para informante. Como o foco é o informante, será analisada apenas a fala deste. Na análise, utilizam-se as classificações de Marcuschi (2006, p. 68) e Chagas (2007).

No Quadro 4, apresentam-se os dados extraídos da entrevista do informante masculino Cicero José ${ }^{6}$ que, em 87 linhas de narrativa, utilizou 16 marcadores conversacionais.

\section{Quadro 4: Entrevista do informante Cicero José}

\begin{tabular}{|c|c|c|c|}
\hline No DE M. C. $^{7}$ & LINHA & M. C. & MOTIVAÇÃO \\
\hline 01 & 15 & mas & Operador argumentativo de contrajunção \\
\hline 02 & 23 & né & Busca de apoio em final de turno \\
\hline 03 & 31 & né & Busca de apoio \\
\hline 04 & 34 & daí & Deu continuidade ao tópico em andamento \\
\hline 05 & 35 & claro & Início do turno \\
\hline 06 & 35 & Então & Início do turno \\
\hline 07 & 37 & aí & Dêitico \\
\hline 08 & 39 & daí & Deu continuidade ao tópico em andamento \\
\hline 09 & 43 & Então & Início do turno \\
\hline 10 & 46 & Então & Sustentação de turno \\
\hline 11 & 56 & né & Como busca de apoio em final de turno \\
\hline 12 & 58 & né & Como busca de apoio \\
\hline 13 & 70 & bom & Iniciador de turno \\
\hline 14 & 82 & aqui ó & Exclamativo \\
\hline 15 & 83 & né & Como busca de apoio em final de turno \\
\hline 16 & 83 & Então & Início do turno \\
\hline
\end{tabular}

Fonte: Dados da Pesquisa 
No Quadro 5, apresentam-se os dados extraídos da entrevista da informante feminina Lídia Lesko da Silva que, em 51 linhas de narrativa, utilizou 38 marcadores conversacionais.

\section{Quadro 5: Entrevista do informante Lídia Lesko da Silva}

\begin{tabular}{|c|c|c|c|}
\hline $\mathrm{N}^{0}$ DE M. C. ${ }^{8}$ & LINHA & M.C. & MOTIVAÇÃO \\
\hline 01 & 5 & $\mathrm{Ah}$ & Indicador de hesitação \\
\hline 02 & 6 & né & Como busca de apoio em final de turno \\
\hline 03 & 6 & E daí & Deu continuidade ao tópico em andamento \\
\hline 04 & 8 & acho eu que & Marca uma opinião \\
\hline 05 & 9 & né, & Como busca de apoio em final de turno \\
\hline 06 & 10 & e daí & Deu continuidade ao tópico em andamento \\
\hline 07 & 10 & né, & Como busca de apoio em final de turno \\
\hline 08 & 10 & e daí & Deu continuidade ao tópico em andamento \\
\hline 09 & 12 & né, & Como busca de apoio em final de turno \\
\hline 10 & 13 & né, & Como busca de apoio em final de turno \\
\hline 11 & 13 & né, & Como busca de apoio em final de turno \\
\hline 12 & 16 & $\mathrm{Ah}$ & Indicador de hesitação \\
\hline 13 & 21 & $\mathrm{Ah}$ & Indicador de hesitação \\
\hline 14 & 21 & qué dizê & Indicador de retificação \\
\hline 15 & 22 & né & Como busca de apoio em final de turno \\
\hline 16 & 22 & $\mathrm{Ah}$ & Tomada de turno \\
\hline 17 & 23 & eu não sei & Manifesta opinião \\
\hline 18 & 23 & assim & Explicativo \\
\hline 19 & 25 & como se diz & Envolver o ouvinte \\
\hline 20 & 27 & ai & Exclamativo \\
\hline 21 & 28 & é ou não é? & Como busca de apoio em final de turno \\
\hline 22 & 30 & né & Busca de apoio e término de turno \\
\hline 23 & 32 & $\mathrm{E}$ & Ideacional \\
\hline 24 & 33 & Sabe? & Como busca de apoio em final de turno \\
\hline 25 & 33 & Então & Ideacional \\
\hline 26 & 36 & é verdade & Tomada de turno \\
\hline 27 & 37 & sabe era desse jeito & Conclusivo \\
\hline 28 & 37 & então eu acho que & Marca uma opinião \\
\hline 29 & 38 & assim, né, & Busca de apoio e término de turno \\
\hline 30 & 38 & não sei mas acho que não, né & Marca uma opinião \\
\hline 31 & 39 & né & Busca de apoio e término de turno \\
\hline 32 & 39 & né & Busca de apoio e término de turno \\
\hline 33 & 39 & não sei como é que é & Hesitação \\
\hline 34 & 44 & então & Ideacional \\
\hline 35 & 45 & né & Busca de apoio e término de turno \\
\hline 36 & 45 & assim, né & Busca de apoio e término de turno \\
\hline 37 & 45 & só mesmo & Ideacional \\
\hline 38 & 48 & né & Busca de apoio e término de turno \\
\hline
\end{tabular}

Fonte: Dados da Pesquisa

Com base no número de marcadores utilizados por ambos os informantes, pode-se confirmar o pressuposto de que o texto falado é permeado por elementos - marcadores conversacionais - desnecessários para o entendimento, mas importantes para deixar a língua falada mais dinâmica e expressiva. 
Os dados levantados demonstram que os marcadores mais aparentes são os denominados simples, compostos por uma palavra. Na entrevista do informante masculino aparecem: mas (linha 15), né (linhas 23, 31, 56,58 e 83), daí (linhas 34 e 39), claro (linha 35), então (linhas 35, 43, 46 e 83), aí (linha 37) e bom (linha 70). A entrevista da informante feminina apresenta os seguintes marcadores simples: Ah (linhas 5, 16, 21, 22), né (linhas 6, 9, 10, 12, 13, 22, 30, 39, 45 e 48), assim (linha 23), ai (linha 27), e (linha 32), sabe? (linha 33), então (linhas 33 e 44).

No que diz respeito aos marcadores compostos, que apresentam um caráter sintagmático, ocorre pouca utilização, principalmente por parte do informante masculino que o emprega apenas uma vez: aqui ó (linha 82). A informante feminina utiliza um pouco mais, empregando marcadores conversacionais compostos por 4 vezes: e daí (linhas 6 e 10), quer dizer (linha 21), assim né (linhas 38 e 45) e só mesmo (linha 45).

O informante Cícero José não apresenta nenhum marcador oracional, ou seja, que corresponda a pequenas orações que apresentam diversos tempos e formas verbais. Lídia Lesko da Silva apresenta algumas como: acho eu que (linha 8), eu não sei (linha 23), como se diz (linha 25), é ou não é? (linha 28), é verdade (linha 36), sabe era esse jeito (linha 37), então eu acho que (linha 37), não sei mas acho que não é (linha 38) e não sei como é que é (linha 39).

A apresentação dos dados de maneira sucinta se deve ao espaço reduzido deste trabalho, o que também não permite a utilização de um corpus maior. Isso, contudo, não impede que se tire algumas conclusões.

\section{CONSIDERAÇÕES FINAIS}

Estudos sociolinguísticos já provaram que há diferenças entre a fala masculina e a feminina em muitos níveis da língua como, por exemplo, na escolha lexical a ser utilizada. $\mathrm{O}$ objetivo deste estudo foi analisar se ocorrem diferenças na utilização de marcadores conversacionais na fala de indivíduos de diferentes gêneros. Não foi possível apresentar uma resposta conclusiva devido à extensão do trabalho, mas procurou-se levantar uma hipótese que pode ser aprofundada em outras pesquisas.

O destaque deste trabalho foi a importância dos marcadores conversacionais para uma conversação espontânea e dinâmica. Ao analisar a motivação dos marcadores conversacionais, percebe-se que, em sua maioria, o indivíduo sente a necessidade de que o ouvinte apoie sua fala, como ocorre, por exemplo, na utilização dos marcadores: né, é ou não é?, sabe?, assim né, entre outros. 
O que se depreende dos dados observados é que na fala da informante feminina ocorrem mais marcadores discursivos. Isso se torna bem visível ao considerar-se que a informante feminina utilizou 38 marcadores em 51 linhas de entrevista, ao passo que o informante masculino utilizou 16 marcadores em 87 linhas, ou seja, apresentou um percentual maior de fala com menos do que a metade dos marcadores.

Os marcadores mais utilizados são os simples. Aliás, a fala do informante masculino é praticamente toda permeada por esse tipo de marcador. Em relação aos compostos, a informante feminina apresenta quatro ocorrências e masculino apenas uma. Já a apresentação de marcadores oracionais somente ocorreu na fala da informante feminina, na maioria das vezes, para afirmar sua opinião.

Neste pequeno recorte, além de apresentar a importância dos marcadores conversacionais, destacou-se que estudos da $\mathrm{AC}$, principalmente no que se refere o tema aqui abordado, é um campo de pesquisa vasto e promissor, que pode ser analisado sob diferentes focos da Linguística.

\section{NOTAS}

1 Quanto à escolaridade, os informantes devem ser alfabetizados, tendo cursado, no máximo, até a quarta série do ensino fundamental. Disponível em: http://twiki.ufba.br/twiki/bin/view/Alib/Metodologia Geral. Acesso em: 20 abr.2015.

2 Disponível em: http://www.filologia.org.br/revista/artigo/7(20)05.htm . Acesso: julho 2011.

3 Informações retiradas do site $<$ http://www.filologia.org.br/revista/37/09.htm>. Acesso: julho 2011.

4 Entre as capitais brasileiras que formam a rede de ponto do ALiB, excetuam-se Palmas e Brasília por serem cidades de criação recente.

5 Chagas tem como base para seu trabalho o modelo de Marcuschi (2005, p. 68) e Urbano (1993,p. 100-101).

6 Os nomes foram divulgados com o consentimento dos informantes.

7 Para M. C. lê-se Marcadores Conversacionais.

8 Para M. C. lê-se Marcadores Conversacionais.

\section{REFERÊNCIAS}

ALtinO, Fabiane Cristina. Atlas Linguístico do Paraná. Tese (Doutorado) - Universidade Estadual de Londrina, Londrina, 2007.

ANDRADE, Maria Lúcia da Cunha Victório de Oliveira. O texto oral e sua aplicação em sala de aula: unidade discursiva e marcadores conversacionais como estruturadores textuais. In: 
CONGRESSO BRASILEIRO DE LÍNGUA PORTUGUESA, 60, 1998, São Paulo. Anais... São Paulo: IP-PUC/SP.

BORBA, Francisco da Silva. Introdução aos estudos linguísticos. São Paulo: Nacional, 1972.

CÂMARA Jr., Joaquim Mattoso. Manual de expressão oral e escrita. 6. ed. Petrópolis: Vozes, 1981.

Chagas, C.H. O texto oral dialogado: a importância dos marcadores conversacionais. Revista Philologus, v. 13, n. 37, Rio de Janeiro, 2007. Disponível em: <http:/www.filologia.org.br/ revista/37/09.htm>. Acesso em: julho 2011.

GALEMBECK, Paulo de Tarso; BLANCO, Luciene Rampazo. Marcadores conversacionais na linguagem jornalística. Revista Philologus, n. 20, Rio de Janeiro, 2001. Disponível em: $<$ http:// www.filologia.org.br/revista/artigo/7(20)05.htm>. Acesso em: julho 2011.

KOCH, Ingedore Villaça et al. Organização tópica da conversação. In: ILARI, R. (org.) Gramática do português falado. v. 2, Campinas: UNICAMP, 1992.

(Org.). Gramática do português falado. 2. ed. v. VI. Campinas: Unicamp/Fapesp, 1997.

MARCUSCHI, Luiz Antônio. Análise da Conversação. 5. ed. São Paulo: Ática, 2006.

Da fala para a escrita: atividades de retextualização. 3. ed. São Paulo: Cortez, 2001.

ONG, Walter. Oralidade e cultura escrita: a tecnologização da palavra. Campinas: Papirus, 1998.

PROJETO DO ATLAS LINGUÍSTICO DO BRASIL: Comitê Nacional, 1999, s.p.

. Disponível em: < http://www.ALiB.ufba.br/>. Vários acessos.

REYZÁBAL, Maria Victoria. A comunicação oral e sua didática. Bauru: EDUSC, 1999.

ROSA, Margaret. Marcadores de atenuação. São Paulo: Contexto, 1992.

SAUSSURE, Ferdinand. Curso de Linguística Geral. 4ª ed., São Paulo: Cultrix, 1972. 